\title{
Study on the Improvement of Students' Grammar Ability in the College English Teaching
}

\author{
Peng Cui \\ Feixian Branch, Linyi University. Feixian, Shandong, China \\ cuipeng2008.ok@163.com
}

\begin{abstract}
Keywords: Portfolio; Portfolio assessment method; College English teaching; Evaluation; Grammar ability
\end{abstract}

\begin{abstract}
It's necessary to find a good way to improve college students' grammar ability. Portfolio assessment is a qualitative evaluation which was formed and developed in the movement of Western education evaluation reform. Teachers can use this kind of evaluation method to guide students to collect and record their own performance. Based on the constructivism theory, the paper carried out a 15-week long experiment in which two classes of students are taught by different teaching method. One class is the experimental group in which students were taught by the portfolio assessment method. The other is control group in which students are used with the traditional grammar teaching method. After the experiment, the students' scores of grammar part were collected and put into the computer to analyze by the spas software. When comparing with the results of pretest and posttest through the independent sample test and the paired samples, we can see that the students in the experimental group made greater improvement than those in the control group. At last, the paper discusses the problems and results conducted and brought in its application, which can be expected some inspiration in the future of English teaching.
\end{abstract}

\section{Introduction}

Ministry of Education of the People's Republic of China advocates scientific teaching evaluation system issued by "English Curriculum Requirements of College Education" in 2010. This evaluation system advocates that students' learning process and results should be scientifically and comprehensively evaluated in the form of Learning Portfolio record, classroom activity, interviews and seminars and other means of formative evaluation.

Portfolio assessment is the assessment method widely applied in the current educational practice. It was introduced into China in the late 20th century and mainly used in the field of basic education. In recent years, Portfolio assessment has been adopted in the college English teaching and its development has been rising.

Grammar teaching in foreign language education has been attracted by scholars once again since the 1990s. In the current teaching practice, we realize that the college students have poor grammar ability. Students lack knowledge of grammar and then cause a series of problems in learning. Under the current circumstance, it is critical to find the right way to solve the learners' grammar problems in teaching. In recent years, portfolio assessment has been used in the English teaching such as the writing courses, reading courses, spoken language teaching and translation courses and has achieved better results. Meanwhile, portfolio assessment is considered to be unity of teaching and it is the combination of learning and measuring.

From what's mentioned above, it is instructive to have the study by using portfolio assessment method to the cultivate and improve the college students' grammar ability in the English teaching. In other words, these three points contributes to the formation of this study.

\section{Literature Review}

Definition of Portfolio Assessment. Portfolio assessment which can also be called Learning Portfolio assessment or students' evaluation is a new qualitative evaluation method. Portfolio Assessment is formed and developed in the West Appraisal Reform in the 1980s and can be used on 
the object by an objective and comprehensive evaluation. Under the guidance of teachers, the programs selected or submitted by portfolio assessment method should be carried out by the students of their own. [1] Meanwhile the portfolio assessment records the students' performance within a period of time and shows the developments of skills in a field, which can give full play to the subjectivity of students and adapt and meet the needs of the new curriculum reform. In this paper, portfolio assessment method is chosen as the research topic to explore its feasibility and effectiveness in college English teaching.

Studies on Portfolio Assessment Abroad. This kind of assessment occurred in the 1960sand it was the refection of criticizing traditional reform movement characterized by quantity in the western educational circle. The portfolio assessment was formed and developed during the western evaluation movement of primary and secondary schools in the 1980s and it has been put into practice since 1990.For the time being, this method has been widely used in the practice of overseas education .[2]

In recent years, Europe, Japan and other countries have been widely used the portfolio assessment in education [3]. Harvard Institute of Education "Project Zero" and many other writing projects in Berkeley University K-12 have adopted this approach and achieved satisfactory results; the national board for the professional teaching standards in America takes the portfolio assessment as the main part in deciding whether the professionals have the quality for the teaching. In Japan, portfolio as first-hand data of quality evaluation is called "dossier" and has been further studied by the combination of more than one way of evaluation [4].

Studies on Portfolio Assessment at Home. Portfolio assessment was brought to China in the late 1980's and was mainly used in the primary education. In recent years, the study of portfolio assessment has emerged in the higher education and college English teaching. The scholars in our country have made some studies concerning portfolio assessment. For example: R.P.Cao, W.X.Zhang (2004) made an experiment on the application of portfolio in the College English Writing teaching [5].X.L.Wu (2008) points out portfolio can enhance the students' ability of self-reflection and self-learning [6].X.H.Chen (2009) explored the method of portfolio assessment in the college English oral teaching [7].X.X.Yin (2010) carried out the applicable study on the portfolio assessment in improving college students' oral ability [8]. Z.J.Wu (2014) taught the English majors by using the portfolio assessment method in the reading teaching [9].

At present, more and more scholars have paid attention to the study of portfolio assessment method, but only at the theoretical level. Meanwhile these studies used in the teaching of English majors and higher vocational students and this teaching method is mostly used in the teaching of reading and writing. The study of portfolio assessment method is seldom used in the English grammar teaching in college.

So this paper puts forward the new teaching model in the grammar teaching that is the grammar teaching based on the portfolio assessment method, which hopes to improve the college students' grammar ability and their comprehensive ability.

\section{Theoretical Support}

Constructivism Theory. The earliest proponent of Constructivism can be traced back to the Swiss Piaget. He is the most influential psychologist in the field of cognitive development. He believes that children gradually construct knowledge about the outside world and then develop their cognitive structure in the process of interaction with the surrounding environment. As a branch of cognitive psychology school, constructivism is also known as structuralism. The important concept in the constructivism theory is schema. As the starting point and the core of cognitive structure, schema refers to the individual perception and thought to the world or the foundation of human understanding towards to the materials around the world. Thus, the formation and change of schema is the essence of cognitive development which is influenced by three processes: assimilation, accommodation, and equilibration.

Some points are thought to be important in the constructivism theory, that is (1) learning is learning is an active and constructive process. Learners can actively and selectively construct the 
meaning of the current things based on previous cognitive structure, not by the way of receiving the information passively. (2)The construction of knowledge is not arbitrary. The important point is to have communication and agreement with others and to be constantly adjusted and amended in the process of construction. Meanwhile, the construction of knowledge will inevitably be influenced by the culture of society at that time. In fact, these differences in the phenomenon itself are a valuable resource. Although constructivism theory attaches great importance to individual self-development of students, it cannot deny the external guide that is the influence of teachers.

\section{Research Methodology}

Hypothesis. Before the experiment, the research questions are included as follows: In the English grammar teaching, can the portfolio assessment method improve college students' grammar ability? Compared with the traditional grammar method, does the portfolio assessment method improve college students' grammar ability better? What enlightenment and functions can the portfolio assessment method bring in the college English teaching? From the questions said above, we can form a hypothesis: the new teaching method that is portfolio assessment method can effectively improve the college students' grammar ability in the English teaching.

Subjects. The subjects chosen from the two natural classes are the freshman in the Linyi University. Of the two classes, one is the experimental Group, the other is control group. All students are majoring in computer and their ages range from 19 years old to 21 years old. They have the similar English learning experience and the same English level. These college students all come to the university by taking the college entrance examination. To be more important, all students have never been trained by the portfolio assessment method. The class one is chose as the experimental Group, and class two is control group. All students are taught by the same teacher that is the author himself.

Instruments. This period includes the pretest, posttest and the teaching materials. The pretest was adopted in September, 2015 and it was from the quality test for college students who enter the college a month later. The post-test was adopted from the final examination in January, 2016. Both testes are given from the Linyi University and have the same difficulty, which has the certain validity and reliability. The textbook used in both classes are the same, that is the new Era College English (Book one).Meanwhile, this book has the clear part in teaching each grammar item.

Procedure. Making the Teachers Know the Importance of Changing the Evaluation Concept. Teachers should establish a new concept of evaluation and the developed concept that all evaluation methods are developed for students. Evaluation should allow students to see their progress and growth in order to enhance their self-confidence and their initiative of learning; students are no longer just the evaluated subjects, they are also the main body of the evaluation. Teachers can have a great help in evaluating students 'knowledge and skills, and can bring the students' emotions, attitudes and values into play.

Determining What Types of Work as the Sample. The purpose of portfolio assessment determines the type of data collection. The achievement file should be selected if the aim of establishing a portfolio is to present the results of students' learning outcomes. [10]If the aim of establishing a portfolio is to understand or diagnose learning problems, the process file should select. For example, the process file in the English learning can be selected such as self-introduction, summary, my performance, my mistakes, and my favorite, etc.

Collecting and Putting Aside the Sample. Students should collect their designed works and then put them into a suitable container such as a folder or notebook, and store it in a suitable place at last. During the process of collecting the material, they can put what they have prepared into the file.

Asking Students to Constantly Evaluate the Portfolio Works. To ensure that students can assess their own work based on established criteria. Let the students sign the date in the self-assessment form in order to track the progress of students in enhancing the ability to make self-assessment. Each a self-assessment form must also be set together with the corresponding works made by students. In addition to self-assessment, students can have the peer assessment in order to learn to objectively and fairly evaluate others, and at the same time they can appreciate the advantages of 
peer with the vision, find their own weakness and take initiative to make greater development.

Arranging for the Given Performance Meeting of Portfolio Assessment. The exchange of information between teachers and students plays an important role in motivating students' portfolio assessment. Otherwise, students will lose their interests when they can't get the chance to show their portfolio. In a word, it is necessary for teachers to regularly allow students to present their portfolio in front of the class and encourage them to exchange their ideas among groups and help students put forward the positive and constructive suggestion.

\section{Results and Discussion}

Results and Discussion of the Pretest. The students in the experimental group (EG) and the control group (CG) took the quality test given by Linyi University in September, 2015. After the test given by the adequate time, the grammar part containing 30 multiple choices are collected, and the students' scores of grammar part were put into the spas software. The results of both two classes are showed as follows:

Table 1 Results of independent samples tests in grammar part (group statistics)

\begin{tabular}{|c|c|c|c|c|}
\hline Group & $\mathrm{N}$ & Mean & Std.Deviation & Std.Error Mean \\
\hline Pretest & & & & \\
EG & 30 & 16.3142 & 3.0435 & .4756 \\
CG & 30 & 16.3710 & 3.4230 & .5913 \\
\hline
\end{tabular}

At the beginning of the semester, the scores of grammar part (30 points in total) were put into the computer and analyzed by the Spas software. Though the independent samples test, we can see that the average score in the EG and CG are at the similar level, that is to say, students of each class have the same grammar ability.

Results and Discussion of the Posttest. At the end of semester, the students in both CG and EG were given the final examination given by Linyi University in January, 2016. The difficulty of the test and the time of test are the same to that of pretest at the beginning of semester in September, 2015. The number of the grammar choice is also same to the numbers in the pretest. After the posttest, all scores in the grammar parts are collected and put into the spas software. The analysis of the results though the independent samples test is as follows:

Table 2 Results of independent samples tests in grammar part (group statistics)

\begin{tabular}{|c|c|c|c|c|}
\hline Group & $\mathrm{N}$ & Mean & Std. Deviation & Std. Error Mean \\
\hline posttest & & & & \\
\hline $\mathrm{EG}$ & 30 & 22.8560 & 4.3890 & .5789 \\
\hline CG & 30 & 18.1032 & 4.0221 & .4761 \\
\hline
\end{tabular}

After the posttest, it can be seen from the table that the scores of students in the experimental group is 22.9 points, while in the control class the score is the 18.1 points. The average score in the EG is 4.8 higher than in the CG .that is to say, the students in both classes have the obvious difference after the 14-week long experiment. 


\section{The Comparison of the Results of the Pretest and Posttest.}

Table 3 Results of paired samples t-test in the EG(paired sample statistics)

\begin{tabular}{|c|c|c|c|c|}
\hline Group & $\mathrm{N}$ & Mean & Std. Deviation & Std. Error Mean \\
\hline EG & & & & \\
pretest & 30 & 16.3142 & 1.5104 & .23882 \\
posttest & 30 & 22.8560 & 1.1712 & .18519 \\
\hline
\end{tabular}

Table 4 Results of paired samples t-test in the CG(paired sample statistics)

\begin{tabular}{|c|c|c|c|c|}
\hline Group & $\mathrm{N}$ & Mean & Std. Deviation & Std. Error Mean \\
\hline CG & & & & \\
pretest & 30 & 16.3142 & 1.3326 & .2423 \\
posttest & 30 & 18.1032 & 1.1808 & .1817 \\
\hline
\end{tabular}

As is mentioned in the table, we can see that the students' average score in the pretest is 16.3 , while the score in the posttest is 22.9 points. By comparison, the scores in the first test are 6.6 points higher than that of posttest. As is said above in the CG, we can see that the students' average score in the pretest is 16.4 , while the score in the posttest is 18.1 points. By comparison, the scores in the first test are 1.7 points higher than that of posttest. $M=22.9>16.4$ indicates that students in the experimental group have made further achievements in the grammar after the 14-week long experiment.

\section{Conclusion}

This paper tests the validity and reliability of teaching portfolio assessment method in the college English teaching. After15-week long experiment, we can draw the conclusion from the results as follows:

When using the portfolio assessment method in the English teaching, the college students' grammar ability has greatly improved. Before the experiment, the students in the experimental group have the same grammar level as those in the control group. When taught by the traditional English grammar method, students have only made the little progress, but the students in the experimental group has the obvious difference and made greater achievements different from those in the control group. The former students' average scores are higher than the latter students by the analysis of independent sample test and paired sample t-test.

The college students' learning attitude in the experimental group has greatly changed. They show the positive and enthusiasm in the discussion of each grammar item and in the cooperation of tackling out each difficult grammar points and the performance of their own portfolio assessment concerning grammar. Under this new teaching method combined with portfolio assessment method in the college grammar teaching, the students have laid the solid foundation of grammar knowledge and enhance their grammar ability, which would be a great help to the master of other aptitudes and comprehensive ability in the English learning.

From what's mentioned above, portfolio assessment method is the effective way in the college grammar teaching and can be expected a better application in the English teaching field.

\section{References}

[1] Y.B.Li: The Theory of Curriculum Assessment. (Shanghai Education Press, China 2012), p.58-59. 
[2] Scott G.Paris, Linda R. Ayres: Becoming Reflective Students and Teachers with Portfolio and Authentic Assessment. (China Light Industry Press, China 2001), p.138-139.

[3] Bill Johnson: The Performance Assessment Handbook. Shanghai: (East China Normal university press, China 2001), p.201-202.

[4] W. James. Popham. Curriculum assessment: What Teachers Needs to Know and Learn. (East China Normal university press, 2003), p.155-156.

[5] R.P. Cao, W.X.Zhang: Foreign language Education, (2004) No.5, p.44-45.

[6] X.L.Wu: Foreign language and Their Teaching, (2014) No.9, p.110-112.

[7] X.H.Chen: Foreign language and Their Teaching, (2009) N0.7, p.76-78.

[8] X.X.Yin: Journal for the Southwest University, (2010) No.2, p.32-33.

[9] Z.J.Wu: Journal for the Southwest University for Nationalities, (2008) No.3, p.56-57.

[10]X L.Chen, .T. Cheng: Interpretation of English Curriculum Standards.(Beijing Normal University Press, China 2002), p.201-202. 